\title{
Reversing global biodiversity declines: Mainstreaming biodiversity conservation into decision-making at national and local scales
}

\author{
Rhema Bjorkland ${ }^{1, *}$ and Ronald Bjorkland ${ }^{2}$ \\ Edited by Paige Omura and Grant A. Knappe
}

\section{HIGHLIGHTS}

- Human activities are directly and indirectly driving an unprecedented decline in the variety of life (biodiversity) on earth. This loss threatens nature's ability to provide the services that are integral to human well-being and social development

- Despite the passage of a global agreement, the Convention on Biological Diversity, the world community has failed to meet targets set for 2020

- Reversing these trends will require national governments to embed socio-economic planning and land use management within national strategies and commitments to biodiversity

The rapid and unprecedented global loss of biodiversity threatens the wide-ranging goods and services that nature provides, endangers human institutions, and portends future scenarios of human-nature relationships that differ significantly from what humans have experienced historically. While numerous national and international responses have been put in place to stem this loss, none have succeeded in significantly reducing its rate. Reasons for these failures are not uniform, but some key identified features include inadequate funding and logistical support, structural weaknesses in targeted actions, and the socio-political systems that interfere with needed transformative changes. This article provides a brief historical background to global-level biodiversity conservation efforts and suggests pathways needed to move forward if the proposed vision of "Living in Harmony with Nature" by 2050 is to be realized. Framing socio-economic and cultural development within the dual crises of biodiversity loss and climate change, and not the other way around, represents the most likely path to success. This effort will require strong actions from communities and institutions, from local to global, to end the

\footnotetext{
${ }^{1}$ Department of Environmental Science and Policy, George Mason University, Fairfax, VA

${ }^{2}$ Birch Grove Environmental Solutions LLC, Greenbelt, MD

*Email: rbjorkla@gmu.edu
}

The authors declare no conflict of interest.

(C) 2021 The Author(s) disconnect between global targets, national commitments, and local actions; reformed mechanisms for funding and other support; and radically improved strategies to galvanize both political will and public support through improved communication.

B iodiversity, the composite richness or variety of organisms in a given environment or space, reflects the wealth and health of nature. It includes diversity within species, between species, and ecosystems and reflects processes that operate at various temporal scales. However, globally biodiversity loss continues at a rate and scale on par with Earth's previous mass extinction events [1]-[3] and undermines the efficiency and effectiveness of ecosystem functioning and nature's ability to support a healthy environment $[3,4]$. The current economic value of nature's goods and services is estimated at more than twice the global GDP [5]. Nature's provision of ecosystem goods and services is integral to human well-being and survival, and their contribution to human development (Fig. 1) support a powerful rationale for conserving biodiversity $[6,7]$. Since the mid-twentieth century, the world community has acknowledged biodiversity loss as one of the most consequential global challenges. This position is the dominant framework around which international efforts to slow or reverse biodiversity loss are deliberated and orchestrated. In 1992, the Convention on Biological Diversity (CBD) in Rio de Janeiro (Rio) was adopted. This landmark international treaty is the first major global instrument focused on protecting biodiversity, the world's critical resource base.

The CBD set the stage for the development of global indicators and actionable targets based on robust assessments. The Convention's 2010 and 2020 goals and targets were set out in the 2002 and 2011-2020 Strategic Plans for Biodiversity, respectively, with the latter establishing the Aichi Biodiversity Targets, a set of global goals aimed at protecting and conserving global biodiversity (CBD, 2010) (1).

One hundred ninety-six nations agreed to meet all 20 time-bound, measurable objectives of these targets by the year 2020, at the latest. These targets were identified to satisfy five strategic goals: addressing underlying causes of biodiversity loss; reducing the direct pressures on biodiversity 


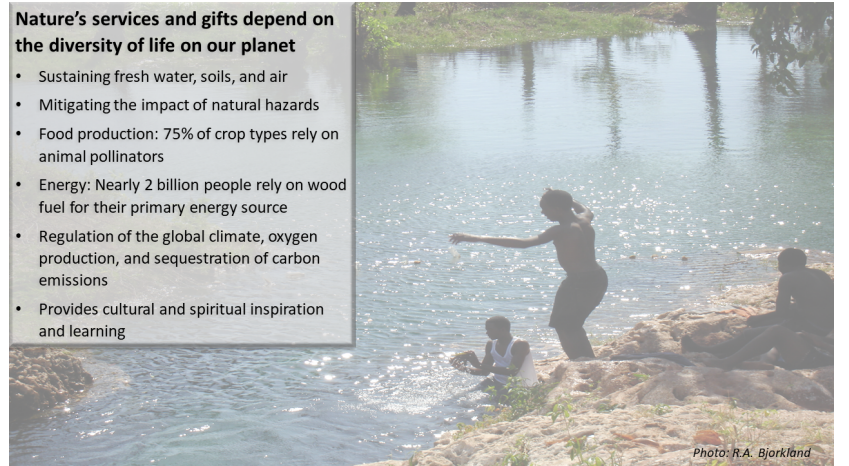

Figure 1: Examples of nature's contribution to people. Biodiversity loss threatens the integrity of ecosystems and their ability to provide the services and gifts that humans rely on.

safeguarding ecosystems, species, and genetic diversity; enhancing the benefits to all from biodiversity and ecosystem services; and promoting participatory planning, knowledge management and capacity building.

Built on the momentum of the 2000 United Nations (UN) Millennium Development Goals, the UN Conference on Sustainable Development, also known as the Rio+20 Conference, promoted the 2030 Agenda for Sustainable Development. The Agenda was adopted by all UN Member States in 2015. An ambitious framework to address a broad range of global challenges that pertain to human welfare now and in the future, the Agenda consists of 169 targets embedded in the 17 goals and calls for action by the world community to end all forms of poverty and promote prosperity while protecting the planet by the year 2030 . Similar to the 2011-2020 Strategic Plan, biodiversity and ecosystem protection feature prominently across many of the targets and goals of the Agenda. This exemplifies the mutually supportive and reinforcing nature of these global initiatives where implementation of one contributes to the achievement of the other. Specifically, Goal 15 of the Agenda is "to protect, restore, and promote sustainable use of terrestrial ecosystems, sustainably manage forests, combat desertification, and halt and reverse land degradation and halt biodiversity loss" (United Nations General Assembly, 2015)(2).

By all measures the rate of biodiversity loss has not slowed in the three decades since the signing of the CBD, and progress toward the Aichi goals and targets (Table I) has been poor $[8,9]$. Furthermore, evidence of an impending tipping point heightens the sense of urgency to address biodiversity loss, with a narrowing window of time and opportunity to reverse this trend [10]-[12]. Moreover, biodiversity loss may interact with other planetary boundaries to increase vulnerability of terrestrial and aquatic systems to changes in tipping points for the global climate and ocean acidity boundaries [13]. The failure to date to meet many biodiversity goals and targets has implications for realizing "Living in Harmony with Nature" (CBD, 2010). The CBD envisions a future where biodiversity is valued, conserved, restored and wisely used, maintaining ecosystem services, sustaining a healthy planet and delivering benefits essential for all people, by 2050 . Implementing the actions and policies established in the already agreed-upon goals and targets and going beyond will require new and ambitious goals, bold strategic initiatives, and significantly increased efforts to prevent the continued erosion of the world's biodiversity and the services it provides $[14,15]$

While there is consensus that bold strategies are needed, the question remains if policy makers will adopt the measures to effect transformative changes that are required to meet stated targets. Global assessments of biodiversity loss and conservation strategies have matured and expanded. However, some of the most critical factors that account for the shortcomings in meeting biodiversity conservation targets include failure to mainstream biodiversity conservation agendas at all governance levels (local to international), inability or unwillingness of governing bodies to incorporate strategies that are holistic in nature and incorporate a long-term commitment to sustainability, and insufficient accounting of societal needs and values [16].

This article describes the strategies, pathways, and targets promoted through international agreements to address global biodiversity loss, with a focus on the Aichi targets and the CBD post-2020 Framework. Drawing from the Intergovernmental Science-Policy Platform on Biodiversity and Ecosystem Services (IPBES) 2019 assessment as the preeminent expert analysis [12], and from observations and conclusions in other sources, this article summarizes priority interventions to facilitate the transformative changes needed to reverse the decline in biodiversity loss. We propose key steps and scenarios that provide pathways to increased conformity of local and domestic decisions with national commitments around reversing global biodiversity declines.

\section{Tackling biodiversity loss - current global strategies and targets}

Efforts to protect nature date back millennia $[17,18]$. However, growth in the number of negotiated instruments and expansion of stakeholder participation in global governance efforts since the mid-twentieth century represent a significant increase in coordinated and encompassing efforts. As sustainable development became the dominant paradigm, the major environmental agreements since then reflect the receptivity of governments to address socio-economic and cultural needs as critical components of species and habitat protection [19]. The CBD agreement encompassed three linked goals: conservation; sustainable use of biological resources; and equitable access to genetic resources and biotechnology. Thus, the Parties to the CBD embraced not only critical issues of the world of nature but also of human cultural, social, and economic provinces. In the Convention's first Strategic Plan adopted in 2002, "More than 180 nations and territories that were party to the CBD committed themselves to a more effective and coherent implementation of the three goals of the Convention and to achieve by 2010 a significant reduction of the current rate of biodiversity loss at the global, regional and national level, which, in turn, would contribute to poverty alleviation and to 


\begin{tabular}{|c|c|}
\hline Goals and targets & Status \\
\hline \multicolumn{2}{|l|}{ Strategic Goal A: Address underlying causes of biodiversity loss across all sectors of society } \\
\hline Target 1 - Awareness of values of biodiversity and tools to conserve and use it sustainably & $\mathrm{M}$ \\
\hline Target 2 - Integration of biodiversity values into local to national development strategies & $\mathrm{P}, \mathrm{M}$ \\
\hline Target 3 - Incentives to foster the conservation and sustainable use of biodiversity & $\mathrm{P}$ \\
\hline Target 4 - Implementation of sustainable production and consumption strategies & $\mathrm{P}$ \\
\hline \multicolumn{2}{|l|}{ Strategic Goal B: Reduce direct pressures on biodiversity and promote sustainable use } \\
\hline Target 5 - Habitat loss, degradation, and fragmentation is significantly reduced & $\mathrm{P}$ \\
\hline Target 6 - Aquatic biota managed sustainably to ensure conservation of biodiversity & $P, U$ \\
\hline Target 7 - Food and forest resources managed sustainably to ensure conservation of biodiversity & $\mathrm{P}, \mathrm{M}$ \\
\hline Target 8 - Pollution is reduced to levels that is not detrimental to ecosystem function and biodiversity & $\mathrm{P}$ \\
\hline Target 9 - Invasive alien species are controlled, eradicated, or prevented from becoming established & $P, G, U$ \\
\hline Target 10 - Climate change impacts are minimized to maintain ecosystem integrity and functioning & $\mathrm{P}$ \\
\hline \multicolumn{2}{|l|}{ Strategic Goal C: Safeguard ecosystems, species, and genetic diversity to improve biodiversity status } \\
\hline $\begin{array}{l}\text { Target } 11 \text { - Protected areas will encompass a minimum of } 17 \% \text { of terrestrial and inland water and } \\
10 \% \text { of coastal and marine areas, globally }\end{array}$ & M,G \\
\hline Target 12 - Species extinctions of threatened species prevented, and conservation status improved & $\mathrm{P}$ \\
\hline $\begin{array}{l}\text { Target } 13 \text { - Genetic diversity of cultivated plants, domesticated animals, and their wild relatives is } \\
\text { maintained, and strategies developed to minimize genetic erosion and safeguard their genetic diversity }\end{array}$ & $\mathrm{P}, \mathrm{M}, \mathrm{U}$ \\
\hline \multicolumn{2}{|l|}{ Strategic Goal D: Enhance the benefits to all from biodiversity and ecosystem services } \\
\hline $\begin{array}{l}\text { Target } 14 \text { - Ecosystems services are restored and safeguarded, with consideration of needs of the } \\
\text { most vulnerable populations }\end{array}$ & $\mathrm{U}$ \\
\hline $\begin{array}{l}\text { Target } 15 \text { - Ecosystem resilience enhanced through conservation and restoration of a minimum } 15 \% \\
\text { of area of degraded ecosystems to contribute to climate change mitigation and adaptation }\end{array}$ & U \\
\hline $\begin{array}{l}\text { Target } 16 \text { - Shared benefits derived from fair and equitable genetic utilization of resources, which will } \\
\text { contribute to the conservation and sustainable use of biodiversity }\end{array}$ & $\mathrm{M}, \mathrm{G}$ \\
\hline \multicolumn{2}{|c|}{ Strategic Goal E: Enhance implementation through participatory planning, knowledge management, and capacity building } \\
\hline $\begin{array}{l}\text { Target } 17 \text { - National Biodiversity Strategy and Action Plans (NBSAPs) developed and commenced } \\
\text { implementation by each Party }\end{array}$ & M,G \\
\hline $\begin{array}{l}\text { Target } 18 \text { - Traditional knowledge relevant for the conservation and sustainable use of biodiversity is } \\
\text { recognized and reflected in the implementation of the Convention with participation of indigenous } \\
\text { and local communities, at all relevant levels }\end{array}$ & $\mathrm{M}, \mathrm{U}$ \\
\hline $\begin{array}{l}\text { Target } 19 \text { - Communication of science base and technologies relating to biodiversity is improved and } \\
\text { widely shared }\end{array}$ & $\mathrm{M}, \mathrm{U}$ \\
\hline $\begin{array}{l}\text { Target } 20 \text { - Financial resources should increase substantially from the current levels, with targets } \\
\text { subject to changes contingent on resource needs assessments developed and reported by the Parti }\end{array}$ & $\mathrm{M}$ \\
\hline
\end{tabular}

TABLE I: The five strategic goals (A-E) and 20 Aichi Biodiversity Targets of the 2011-2020 Strategic Plan adopted by the Parties to the Convention on Biological Diversity for Biodiversity in 2010 in Nagoya, Japan. Completion date of all targets was 2020 except targets 10,16 , and 17 which was 2015. Primary theme of each target is in bold lettering. Status of progress toward achievement of elements of each target is noted ( $\mathrm{P}=$ Poor; $\mathrm{M}=$ Moderate; $\mathrm{G}=$ Good; $\mathrm{U}=$ Unknown) based on assessment made by Diaz et al. 2019 . The presence of more than one status score in some of the targets represents the assessment of multiple elements in each of the targets. Diaz et al based their assessments on "quantitative analysis of indicators, a systematic review of the literature, fifth National Reports to the Convention on Biological Diversity, and available information on countries' stated intentions to implement additional actions by 2020."

the benefit of all life on Earth" (CBD, 2010). These goals would also satisfy one of the eight 2000-2015 Millennium Development Goals, namely a significant reduction in the rate of biodiversity loss [20]. Some observers of international agreements view the expansive grasp and architecture of CBD as emblematic of recent international agreements and reflect the complexity, obstacles, optional pathways forward, lessons learned, and the nature and dynamics of contemporary international environmental politics.

Against the backdrop of continued biodiversity loss, nations made further commitments to a 2020 timeline to reverse the trend in biodiversity loss. The CBD adopted the 2011-2020 Strategic Plan on Biodiversity which set five strategic goals and the associated Aichi Targets. The Aichi Targets cover a range of development-related issues that are aligned with several UN Sustainable Development Goals (SDGs) [21]. While the Aichi Targets were promoted as a major breakthrough toward achieving reduction in biodiversity loss, with some notable exceptions (e.g., Target 11, the increase in protected area coverage), achievements generally were woefully lacking, none of the targets were fully met, and only a small number of indicators were fully realized at the end of the Plan period [15, 22]-[24]. The shortfall was attributable to multiple root causes, including issues pertaining to the target framework itself and inability of member states to fully support or commit to targets and goals. Table II summarizes frequently cited reasons for the failure to meet CBD goals and targets.

Following the adoption of the 2011-2020 Strategic Plan and the Aichi Targets, 94 nations supported the 


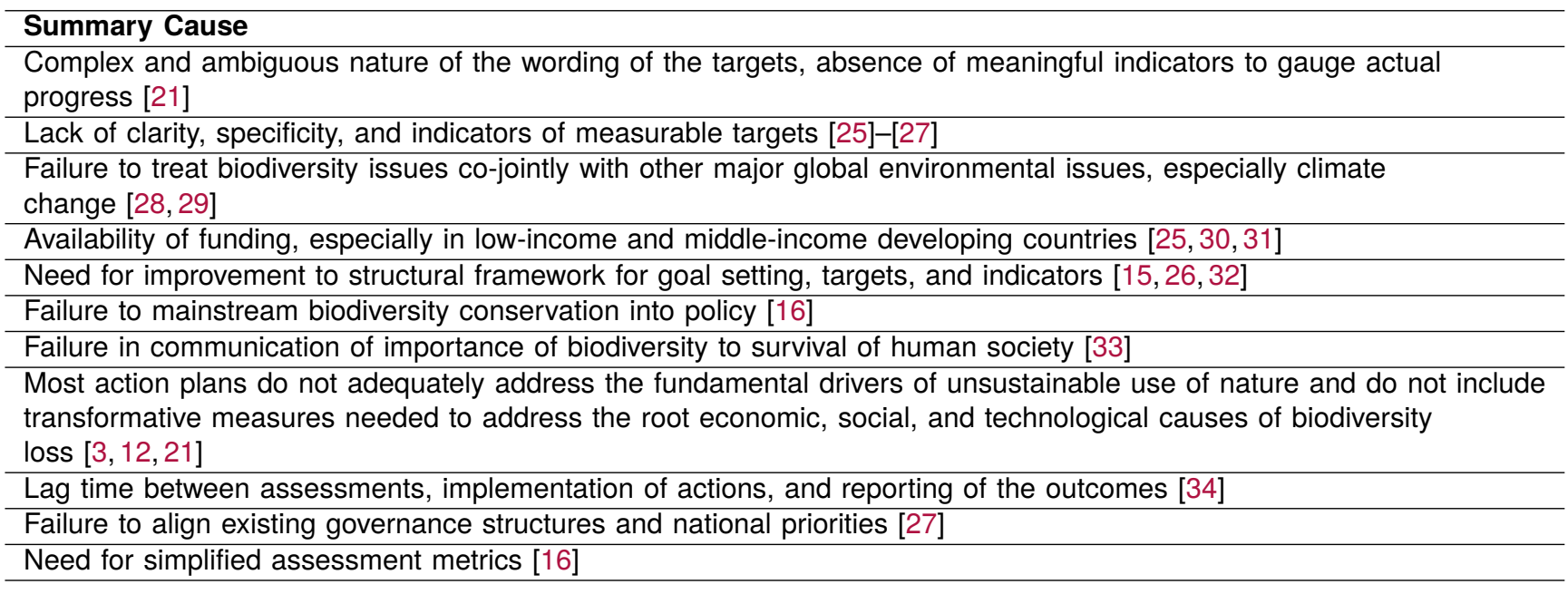

TABLE II: Main causes cited for failure to meet CBD targets

establishment of the Intergovernmental Science-Policy Platform on Biodiversity and Ecosystem Services (IPBES) in 2012. Established as an independent intergovernmental body, the IPBES adapted the experiences of the older Intergovernmental Panel on Climate Change to build political relevance, oversee the integration and representation of diverse knowledge forms, and address issues of public accountability and stakeholder participation. This model enhanced the sense of ownership within and commitment to the IPBES process $[35,36]$. IPBES provides a structured dialog platform to facilitate communication and information sharing between scientists and knowledge holders, and policymakers, for the establishment of legitimate and authoritative outputs. IPBES works in four complementary thematic areas: regional and global level assessments on specific biodiversity themes; policy support through identification of relevant tools and methodologies; capacity building to meet knowledge and data needs; and communication and outreach to ensure the broadest impact of its biodiversity conservation efforts.

The failure to meet conservation targets has fostered a growing sense of urgency to enact effective policies that will protect species and habitats and bend the arc of biodiversity loss. To this end, the 15th Conference of Parties (COP) will meet in Kunming, Yunnan Province, the People's Republic of China, in October 2021. The primary goals of the 15th COP are a review of the achievements and strategies of the CBD's 2011-2020 Strategic Plan for Biodiversity and the adoption of the post-2020 global biodiversity framework as a major pillar towards achieving the 2050 vision of "Living in Harmony with Nature."

\section{Going forward - The 2050 vision of "Living in Harmony with Nature"}

The post-2020 CBD framework, upon which initiatives will be implemented and indicators identified, is grounded in the vision of "Living in Harmony with Nature" by the year 2050. Armed with the state-of-the-art IPBES global assessment and future scenario models, the world entered the post-2020 period with progress on some Aichi Targets, but none fully met [25]. For example, progress towards protection of $10 \%$ of the global oceans has been driven primarily by recent large Marine Protected Area (MPA) designations made by the 14-country High-Level Panel for a Sustainable Ocean Economy. However, with just 20 of the largest MPAs accounting for almost two-thirds of the global coverage in 2019 , there is concern ecologically representative and other important marine areas remain underrepresented [37, 38].

Implementation and enforcement of the newly designated MPAs, complementarity with other accords including the prospective new Biodiversity Beyond National Jurisdiction Treaty, and increasing level of ambition, are challenges going forward. Additionally, terrestrial and marine environments are the focus of targets and indicators, but some conservationists argue that freshwater systems should be elevated to the third ecological realm that deserves legal and scientific prominence in future frameworks and strategies [39]. There are encouraging signs that the assessment and review of the Aichi Targets and indicators are shaping a 2050 framework that will have relevance and utility for a broad suite of biodiversity and other related agreements (e.g., RAMSAR, CITES, UN Framework Convention on Climate Change). The Aichi goals and targets are shaping proposals for a 2050 framework based on more outcome-oriented targets. The post-2020 framework strives for continued momentum towards mainstreaming biodiversity across all sectors. CBD/POST2020/PREP/2/1(3).

\section{Mainstreaming biodiversity for transformative change}

The IPBES 2019 assessment, which revealed a sustained deterioration of biodiversity metrics and an acceleration of the direct and indirect drivers of this decline, also noted the opportunity to conserve and restore nature, and ultimately meet global societal goals, is possible only if transformative changes and mainstreaming biodiversity are undertaken on an urgent basis. Transformative changes for biodiversity conservation imply fundamental and system-wide 
reorganization, including paradigms and goals, across economic, social, political, and technological factors. Considerable attention has been given to fostering this change, but key barriers to biodiversity mainstreaming remain: short-term economic gains by the primary productive sectors; fragmented decision-making; and limited communication among stakeholders $[34,40]$. Our review examines these barriers and proposes policies to support biodiversity mainstreaming in three critical areas: the disparity gap between commitments and action; funding sources and mechanisms; and communication of the tangible implications of biodiversity loss.

Ending the disconnect between global targets, national commitments, and local action: National commitments to the CBD targets are met through preparation and submission of National Biodiversity Strategic Action Plans (NBSAPs). These international commitments require integration into domestic policies, agendas, and targets. Governments should include and elevate the NBSAPs goals within national land use, environmental management, and socio-economic development plans. Linking community-centered conservation to robust NBSAPs is a crucial pathway for the post-2020 global biodiversity framework. This linkage may incorporate expanded roles and utilization of the capabilities of sub-national governments, cities, local authorities, and community organizations to implement policy decisions and action plans [41].

Not surprisingly, governments will require a more effective and timelier process to develop and modify the NBSAPs and additional mechanisms for reviewing implementation progress, improving transparency, and accounting for the cumulative effect of aggregate decisions that contribute to biodiversity loss. This endeavor is important and potentially more challenging for the smaller but biologically significant habitats outside the protected area networks. Ambitious conservation efforts and food system transformation are central to an effective post-2020 biodiversity strategy [14], but developing nations in particular, face tremendous obstacles in revolutionizing land use and agricultural policy in a competitive, telecoupled global marketplace. The most effective application of IPBES assessments will require robust, effective, and accessible tools developed for sub-national and local levels where most policy and management decisions affecting biodiversity and ecosystem services are made. Effective application and dissemination of the global assessments at these scales remains a critical challenge [42]. Providing opportunities for community input to the assessments and developing tools and approaches stakeholders understand are essential for securing local support [43]. The success of biodiversity conservation efforts will depend on galvanizing public support for policies and directives that protect and enhance protection of populations, species, and their habitats. This will entail identifying goals, targets, scale-appropriate action plans, and indicators that effectively communicate to all stakeholders the urgency of the problem and a transparent system that monitors the progress of actions taken [16, 27]. Future actions need to accommodate flexible and dynamic approaches and emphasize actions that embrace robust metrics that are appropriate at the scale of interest and at which biodiversity change occurs [44].

These challenges are an element of a larger issue: ecological systems are highly likely to operate at time scales that do not match those of human decision-making. Government officials and other policy leaders often consider it politically opportune to put short-term gains ahead of longer-term decisions based on environmental sustainability and which may be more challenging to affirm in a political arena of multiple competing needs. This tension in the value of benefits realized is a major factor in the substantive gap between rhetoric, goals, and implementation [45]. It is important to recognize that the NBSAPs targets are an important first step on the path to bending the curve on biodiversity loss. There is an absence of mechanisms that incentivize longer-term planning and decision-making. Additionally, there are few consequences for inaction or failure to adopt policies that support sustainability. In 2016, Parties to the CBD agreed to a pilot voluntary peer-review mechanism to encourage transparency and promote feedback on progress towards meeting national commitments (CBD 2016)(4). This process can mobilize the development of standards for the implementation of biodiversity agreements and improve performance in meeting targets.

Revolutionizing funding: Environmental concerns, particularly biodiversity loss and climate change, were among the top short- and long-term risks identified by the two most recent World Economic Forum's Global Risks Report [46]. Stressing the need for bold and immediate action to address these environmental challenges, the 2020 Report noted "Opting to ride out the current period in the hope that the global system will 'snap back' runs the risk of missing crucial windows to address pressing challenges. On key issues such as the economy, the environment, technology and public health, stakeholders must find ways to act quickly and with purpose within an unsettled global landscape." These observations and those made in numerous other analyses clearly demonstrate that based solely on financial metrics, the benefits derived from investments to protect biodiversity significantly exceed costs $[37,47]$. However, the effects of inadequate financial, technological, and institutional support for biodiversity protection will continue to mount and increasingly impact global scale processes such as climate change and threaten the stability and well-being of interconnected institutions that support the human community, such as food security, health services, business endeavors, Indigenous community livelihood, and cultural development.

Failure to meet biodiversity conservation targets are linked, in part, to financial and socio-political costs [23]. Despite the need for continuous and long-term funding, the overall costs are small relative to other global investments. For example, the cost to protect 30 percent of the world's land and ocean areas and manage them effectively by 2030 would require an annual investment of 140 billion USD [47], or "equivalent to only 0.16 
$\%$ of global GDP, less than one-third of the global government subsidies currently supporting activities that destroy Nature" $[47,48]$. Current efforts to address the COVID-19 pandemic provide instructive lessons on the impact of large-scale, global initiatives involving massive resource investments and mechanisms to secure and disburse the resources. This knowledge can be used to guide strategies and techniques to secure commitments and support for biodiversity conservation initiatives. Investments in wildlife and habitat protection are a mainline defense against future zoonosis outbreaks. The clear link between habitat destruction and wildlife trade, both legal and illegal, and diseases such as Ebola, Nipah virus infection, and SARS, are strong motivators to provide the financial and technical resources. However, to date and with few exceptions, most countries have not identified nature-based investments or policies in their economic stimulus proposals despite substantial evidence that the rate of emergence of novel diseases is increasing as are their economic impacts $[49,50]$.

In addition to the call for substantially increased financial and other resource support to implement biodiversity conservation measures, there is growing acknowledgement of the intrinsic link between biodiversity and the business communities, through the financing and/or underwriting of business ventures. Because economic activities depend on and impact biodiversity and the ecosystem services in multiple ways, the business sector is in a unique position and can play a critical role in creating new pathways in all activity sectors to protect biodiversity. Pillars supporting this transformative shift include incorporating biodiversity safeguards in their strategies; setting environmental protection and conservation targets, especially those that directly impact biodiversity; assessing environmental risk where dependencies and/or impacts on biodiversity are high; and evaluating and actively pursuing opportunities to reduce negative impacts and enhance positive impacts on biodiversity through activities such as no net loss [51].

The COVID-19 pandemic offers valuable insight into the ability and strategies of the world community to address critical, global challenges. The responses to the dramatic impacts on global health, economies, and institutions have generally entailed rapid adoption of principles and action plans to limit the contagion and economic stimuli initiatives to support individual national economies. Efforts to implement effective biodiversity conservation initiatives will require a similar commitment to economic investments and follow-through action by all parties, including governmental bodies, the business sector, and other major stakeholders. Such a stimulus plan will not only provide the resources required to implement measurable actions, but it will also signal the level of engagement the contributing bodies are willing to invest in protecting this natural heritage. Coincidentally, the financial support provided for biodiversity conservation will simultaneously support some of the targets of the UN Sustainable Development Goals and the 2016 Paris Climate Agreement.
Communication: Addressing the difficult questions and revamping the messaging techniques: The CBD provides that the post-2020 framework should be accompanied by an inspirational and motivating 2030 Mission goal as a steppingstone towards attaining the overall goals of the 2050 vision "Living in Harmony with Nature". The effort to bend the curve on biodiversity loss of biodiversity and put nature on a path to recovery envisions at least $30 \%$ of land and sea areas conserved by 2030 . This transformative change in the stewardship will require a significant shift in governance and policy making and how the decisions and actions are communicated to the general community. These efforts will entail difficult conversations about and follow-on actions on issues of human population size, lifestyle, a reduced but more equitable standards of living, and value systems [52].

In contrast to the conclusions of numerous studies, the meta-analyses on biodiversity time series have shown that at the local level biodiversity in some regions of the world is either stable or increasing. However, the biodiversity undergoes shifts in assemblages and that these shifts occur more quickly in marine ecosystems [53,54]. These changes have important implications for biodiversity goals and targets, especially numeric-based indicators and area-based conservation measures. These observations underscore the importance of studying changes in species composition at smaller scales and how changes in local diversity may impact the resilience of ecosystem functions and services [10]. It may be difficult to assess the impact of spatial scale, sample size, and biodiversity measures on cross-study syntheses referenced, and recent studies evaluated sources of inaccuracy and imprecision in study-level and cross-study estimates of biodiversity differences [55]. Effective conservation strategies will need to continuously assess biodiversity trends at smaller scales to ensure messaging is nuanced and encourages action and redress [56]. There are many examples that show losses can be halted or even reversed [3], and some researchers argue that the focus on biodiversity loss has overshadowed conservation successes and weakens the efforts to motivate and support initiatives [56]. Discourse on sustainable development should include the linkage between biodiversity and planetary boundaries and undercut a tendency towards optimism bias without inducing inaction and despair [13].

If the goal is to increase public support for mainstreaming biodiversity conservation policies, then governments and other stakeholders should consider revamping strategies to communicate science-based assessments to the community because stakeholder participation engenders more durable decision-making outcomes. More effective communication will require a better understanding of how information about biodiversity, and nature in general, is perceived and how it can be integrated into the socio-economic fabric of the affected communities. Addressing the energy-food-water-sanitation nexus will be key to achieving biodiversity targets, and this will require a high level of transparency, effective communication, and participation by the communities affected by the 
agreements and action plans. The framework and operational mechanisms of these strategies should be fashioned to adapt to the diverse cultural, religious, and socio-economic perspectives on the relationship between nature and a good quality of life [57].

\section{Conclusions}

The response to the biodiversity crisis has parallels to, and is reminiscent of, the global response to climate change: actions taken to date are underwhelming to the task and have not changed the trajectory. Bending the curve on biodiversity loss will necessitate transformative changes that will embed macroeconomic, fiscal, monetary, and agricultural policies and goals within the larger national plan to protect nature's ability to sustain life. The fear of taming today's economic engine has whittled the political will for fundamental and far-reaching change in political and governance systems that are tied to short-term cycles. Resisting the incentive to make short-term gains against future adverse impacts will require new formulas and platforms. The cost to the global and national economies, human dislocation, and suffering resulting from failure to arrest biodiversity loss is considerably greater than the cost of reversing the trends. Consideration should be given to explicitly naming human health as an ecosystem service [58].

A discussion about advancing this concept is timely, given the undertaking in the Leaders' Pledge for Nature to put "biodiversity, climate, and the environment at the heart of COVID-19 recovery strategies and investments as well as national and international development and cooperation." The approaches needed for sustainability and transformative change such as those outlined in the IPBES assessment are not controversial, but the task of developing tailored and innovative strategies remains a significant challenge. It is widely recognized that strategic actions to solve biodiversity loss, climate change, and human welfare issues are intertwined at all governance levels. Awareness of the need to mainstream biodiversity is explicit in many NBSAPs [59].

This reinforces the importance of the need to understand, identify and remove the barriers to making biodiversity targets a central theme of national development. We agree with Bradshaw and colleagues that there is no shortage of evidence-based solutions by world experts across many disciplines, and averting the twin catastrophes of biodiversity loss and climate change will require the legitimate and authoritative governance mechanisms that operate at scales beyond the typical two to six-year political cycles. Attention should be given to setting a separate sub-target in the post-2020 frame for incorporating under-represented ecoregions in protected area networks. It is also important to recognize that building support for raising the level of ambition for targets in the post-2020 framework will require addressing legitimate concerns of capacity building. The triumvirate challenges of biodiversity loss, climate change, and human welfare are expansive and almost immeasurable, but the appropriate application of technical, management and governance tools can provide a path forward to realize the
2050 vision of "Living in Harmony with Nature". Just as there is an urgency to address the drivers and probable impacts of climate change, the rapid loss of biodiversity deserves immediate and appropriate attention.

\section{Acknowledgements}

We thank the reviewers for their helpful comments and insights. We also thank our families for their support and for inspiring us to work toward improving the present and safeguarding the future.

\section{Citation}

Bjorkland, R. \& Bjorkland, R. Reversing global biodiversity declines: Mainstreaming biodiversity conservation into decision-making at national and local scales. MIT Science Policy Review 2, 31-39 (2021). https: //doi.org/10.38105/spr.c3vlezkmiz.

\section{Open Access}

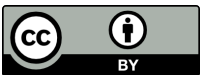

This MIT Science Policy Review article is licensed under a Creative Commons Attribution 4.0 International License, which permits use, sharing, adaptation, distribution and reproduction in any medium or format, as long as you give appropriate credit to the original author(s) and the source, provide a link to the Creative Commons license, and indicate if changes were made. The images or other third party material in this article are included in the article's Creative Commons license, unless indicated otherwise in a credit line to the material. If material is not included in the article's Creative Commons license and your intended use is not permitted by statutory regulation or exceeds the permitted use, you will need to obtain permission directly from the copyright holder. To view a copy of this license, visit http://creativecommons.org/licenses/ by $/ 4.0 /$.

\section{Legislation Cited}

(1) CBD.(2010). CBD/COP/DEC/X/2. The Strategic Plan for Biodiversity 2011-2020 and the Aichi Biodiversity Targets. Convention on Biological Diversity. https://www.cbd.int/ doc/decisions/cop-10/cop-10-dec-02-en.pdf

(2) United Nations General Assembly. (2015). Transforming Our World: The 2030 Agenda for Sustainable Development. Draft resolution referred to the United Nations summit for the adoption of the post-2015 development agenda by the General Assembly at its sixty-ninth session. UN Doc. A/70/L.1 of 18 September 2015. https://sdgs.un.org/2030agenda

(3) CBD. (2020). CBD/POST2020/PREP/2/1. Update of the zero draft of the post-2020 global biodiversity framework. UN Doc. Secretariat, Convention on Biological Diversity. https://www.cbd.int/doc/c/3064/749a/ 0 f65ac7f9def86707f 4eaefa/post2020-prep-02-01en.pdf

(4) CBD. (2016). CBD/COP/DEC/XIII/25. A Methodology for Voluntary Peer Review of the Revision and Implementation of National Biodiversity Strategies and Action Plans. Available from: https://www.cbd.int/doc/meetings/cop/cop13/information/cop-13-inf-02-en.pdf

\section{References}

[1] Ceballos, G. et al. Accelerated modern human-induced species losses: Entering the sixth mass extinction. Sci. Adv. 1, e1400253 (2015). https://doi.org/10.1126/sciadv.1400253. 
[2] Barnosky, A. D. et al. Has the earth's sixth mass extinction already arrived? Nature 471, 51-57 (2011). https://doi. org/10.1038/nature09678.

[3] Johnson, C. N. et al. Biodiversity losses and conservation responses in the anthropocene. Science 356, 270-275 (2017). https://doi.org/10.1126/science.aam9317.

[4] Roe, D. Biodiversity loss-more than an environmental emergency. Lancet Planet. Health 3, e287-e289 (2019). https : //doi.org/10.1016/S2542-5196(19)30113-5.

[5] Costanza, R. et al. Changes in the global value of ecosystem services. Glob. Environ. Change 26, 152-158 (2014). https: //doi.org/10.1016/j.gloenvcha.2014.04.002.

[6] Chaplin-Kramer, R. et al. Global modeling of nature's contributions to people. Science 366, 255-258 (2019). https : //doid.org/10.1126/science.aaw3372.

[7] Djoghlaf, D. A. Reversing biodiversity loss: A key dimension for human development. Biodiversity 11, 2-4 (2010). https: //doi.org/10.1080/14888386.2010.9712638.

[8] Butchart, S. H. M. et al. Global biodiversity: Indicators of recent declines. Science 328, 1164-1168 (2010). https : / / doi . org/ 10.1126/science.1187512.

[9] Díaz, S. et al. Pervasive human-driven decline of life on earth points to the need for transformative change. Science 366, eaax3100 (2019). http://doi.org/10.1126/science. aax3100.

[10] Newbold, T. et al. Has land use pushed terrestrial biodiversity beyond the planetary boundary? A global assessment. Science 353, 288-291 (2016). https: //doi.org/10.1126/science.aaf2201.

[11] Mace, G. M. et al. Approaches to defining a planetary boundary for biodiversity. Glob. Environ. Change 28, 289-297 (2014). https://doi.org/10.1016/j.gloenvcha.2014.07.009.

[12] Díaz, S. M. et al. The global assessment report on biodiversity and ecosystem services: Summary for policy makers. Tech. Rep., Intergovernmental Science-Policy Platform on Biodiversity and Ecosystem Services (2019).

[13] Rockström, J. et al. A safe operating space for humanity. Nature 461, 472-475 (2009). https://doi.org/10.1038/ $461472 \mathrm{a}$.

[14] Leclère, D. et al. Bending the curve of terrestrial biodiversity needs an integrated strategy. Nature 585, 551-556 (2020). https://doi.org/10.1038/s41586-020-2705-y.

[15] Díaz, S. et al. Set ambitious goals for biodiversity and sustainability. Science 370, 411-413 (2020). http://doi. org/10.1126/science.abe1530.

[16] Rounsevell, M. D. A. et al. A biodiversity target based on species extinctions. Science 368, 1193-1195 (2020). https://doi. org/10.1126/science.aba6592.

[17] Arjjumend, H., Koutouki, K. \& Alam, S. Evolution of international governance of biodiversity. JGR 3, 1-15 (2016).

[18] Le Prestre, P. G. Governing global biodiversity: The evolution and implementation of the convention on biological diversity (Routledge, 2017).

[19] Azizi, D., Biermann, F. \& Kim, R. E. Policy integration for sustainable development through multilateral environmental agreements: An empirical analysis, 2007-2016. Glob. Gov. 25, 445-475 (2019). https://doi.org/10.1163/1942672002503005.

[20] World Bank. Millennium development goals.

[21] Butchart, S. H., Di Marco, M. \& Watson, J. E. Formulating smart commitments on biodiversity: lessons from the Aichi targets. Conserv. Lett. 9, 457-468 (2016). https://doi.org/10. $1111 /$ conl.12278.

[22] Driscoll, D. A. et al. A biodiversity-crisis hierarchy to evaluate and refine conservation indicators. Nat. Ecol. Evol. 2, 775-781 (2018). https://doi.org/10.1038/s41559-018-05048.

[23] Xu, H. et al. Ensuring effective implementation of the post-2020 global biodiversity targets. Nat. Ecol. Evol. 5, 411-418 (2021). https://doi.org/10.1038/s41559-020-01375-y.
[24] Hill, R. et al. A social-ecological systems analysis of impediments to delivery of the Aichi 2020 targets and potentially more effective pathways to the conservation of biodiversity. Glob. Environ. Change 34, 22-34 (2015). https://doi.org/10. 1016/j.gloenvcha.2015.04.005.

[25] Maxwell, S. L. et al. Being smart about SMART environmental targets. Science 347, 1075-1076 (2015). https : //doi/org/ $10.1126 /$ science.aaa1451.

[26] Mace, G. M. et al. Aiming higher to bend the curve of biodiversity loss. Nat. Sustain. 1, 448-451 (2018). https : / doi .org/10. 1038/s41893-018-0130-0.

[27] Green, E. J. et al. Relating characteristics of global biodiversity targets to reported progress. Conserv. Biol. 33, 1360-1369 (2019). https://doi.org/10.1111/cobi.13322.

[28] Arneth, A. et al. Post-2020 biodiversity targets need to embrace climate change. PNAS 117, 30882-30891 (2020). https:// doi.org/10.1073/pnas.2009584117.

[29] Seddon, N. et al. Understanding the value and limits of nature-based solutions to climate change and other global challenges. Phil. Trans. R. Soc. B 375, 20190120 (2020). https://doi.org/10.1098/rstb.2019.0120.

[30] Hein, L., Miller, D. C. \& De Groot, R. Payments for ecosystem services and the financing of global biodiversity conservation. Curr. Opin. Environ. Sustain. 5, 87-93 (2013). https://doi. org/10.1016/j.cosust.2012.12.004.

[31] Tittensor, D. P. et al. A mid-term analysis of progress toward international biodiversity targets. Science 346, 241-244 (2014). https://doi/org/10.1126/science.1257484.

[32] Mcowen, C. J. et al. Sufficiency and suitability of global biodiversity indicators for monitoring progress to 2020 targets. Conserv. Lett. 9, 489-494 (2016). https://doi.org/10. $1111 /$ conl.12329.

[33] Pennekamp, F. et al. Biodiversity increases and decreases ecosystem stability. Nature 563, 109-112 (2018). https: //doi.org/10.1038/s41586-018-0627-8.

[34] Leadley, P. W. et al. Progress towards the Aichi biodiversity targets: An assessment of biodiversity trends, policy scenarios and key actions. Tech. Rep., Secretariat of the Convention on Biological Diversity (2014).

[35] Esguerra, A., Beck, S. \& Lidskog, R. Stakeholder engagement in the making: IPBES legitimization politics. Glob. Environ. Polit. 17 59-76 (2017). https: //doi.org/10.1162/GLEP_a_00390.

[36] Beck, S. et al. Towards a reflexive turn in the governance of global environmental expertise. the cases of the IPCC and the IPBES. GAIA 23, 80-87 (2014). https://doi.org/10. 14512/gaia.23.2.4.

[37] UNEP-WCMC, IUCN. Protected planet: The world database on protected areas (WDPA), the global database on protected areas management effectiveness (GD-PAME). Tech. Rep. (2019).

[38] Gannon, P. et al. Editorial essay: An update on progress towards aichi biodiversity target 11. Parks 25, 7-18 (2019). https:// doi.org/10.2305/IUCN. CH.2019.PARKA.S-25-2PG.en.

[39] van Rees, C. B. et al. Safeguarding freshwater life beyond 2020: Recommendations for the new global biodiversity framework from the european experience. Conserv. Lett. 14, e12771 (2021). https://doi.org/10.1111/conl.12771.

[40] Chandra, A. \& Idrisova, A. Convention on biological diversity: a review of national challenges and opportunities for implementation. Biodivers. Conserv. 20, 3295-3316 (2011). https://doi.org/10.1007/s10531-011-0141-x.

[41] Armitage, D., Mbatha, P., Muhl, E.-K., Rice, W. \& Sowman, M. Governance principles for community-centered conservation in the post-2020 global biodiversity framework. Conserv. Sci. Prac. 2, e160 (2020). https://doi.org/10.1111/csp2.160.

[42] Ruckelshaus, M. H. et al. The IPBES global assessment: Pathways to action. Trends Ecol. Evol. 35, 407-414 (2020). https://doi.org/10.1016/j.tree.2020.01.009.

[43] Theobald, D. M. et al. Incorporating biological information in local land-use decision making: designing a system for conservation 
planning. Landsc. Ecol. 15, 35-45 (2000). https: // doi . org/ 10.1023/A:1008165311026.

[44] Burgass, M. J. et al. Three key considerations for biodiversity conservation in multilateral agreements. Conserv. Lett. 14, e12764 (2020). https://doi.org/10.1111/conl.12764.

[45] Wilson, R. S. et al. A typology of time-scale mismatches and behavioral interventions to diagnose and solve conservation problems. Conserv. Biol. 30, 42-49 (2016). https://doi. org/10.1111/cobi.12632.

[46] World Economic Forum. The global risk report 2020. Tech. Rep. (2020).

[47] Waldron, A. et al. Protecting 30\% of the planet for nature: costs, benefits and economic implications. Tech. Rep. (2020).

[48] Dasgupta, P. The Economics of Biodiversity: the Dasgupta Review. (HM Treasury, 2021).

[49] McElwee, P. et al. Ensuring a post-COVID economic agenda tackles global biodiversity loss. One Earth 3, 448-461 (2020). https://doi.org/10.1016/j.oneear.2020.09.011.

[50] Dobson, A. P. et al. Ecology and economics for pandemic prevention. Science 369, 379-381 (2020). https: / / doi . org/ $10.1126 /$ science.abc3189.

[51] Global Canopy and Initiative, UNEP Finance, et al. Beyond 'business as usual': Biodiversity targets and finance; managing biodiversity risks across business sectors. Tech. Rep. (2020).

[52] Bradshaw, C. J. A. et al. Underestimating the challenges of avoiding a ghastly future. Front. Conserv. Sci. 1, 615419 (2021). https://doi.org/10.3389/fcosc.2020.615419.

[53] Blowes, S. A. et al. The geography of biodiversity change in marine and terrestrial assemblages. Science 366, 339-345 (2019). https://doi.org/10.1126/science.aaw1620.

[54] Vellend, M. et al. Global meta-analysis reveals no net change in local-scale plant biodiversity over time. PNAS 110, 19456-19459 (2013). https://doi.org/10.1073/pnas.1312779110.

[55] Spake, R. et al. Implications of scale dependence for cross-study syntheses of biodiversity differences. Eco. Lett. 24, 374-390 (2021). https://doi.org/10.1111/ele.13641.

[56] Leung, B. et al. Clustered versus catastrophic global vertebrate declines. Nature 588, 267-271 (2021). https://doi.org/ $10.1038 / \mathrm{s} 41586-020-2920-6$.

[57] Díaz, S. et al. The IPBES conceptual framework - connecting nature and people. Curr. Opin. Environ. Sustain. 14, 1-16 (2015). https://doi.org/10.1016/j.cosust.2014.11.002.

[58] Levy, K., Daily, G. \& Myers, S. S. Human Health as an Ecosystem Service: A Conceptual Framework (Springer New York, 2012). https://doi.org/10.1007/978-1-4419-0633-5_14.

[59] Whitehorn, P. R. et al. Mainstreaming biodiversity: A review of national strategies. Bio. Conserv. 235, 157-163 (2019). https: //doi.org/10.1016/j.biocon.2019.04.016. 